\title{
Traduzindo e Retraduzindo Mundos Textuais em The Handmaid's Tale
}

\section{Translating and Retranslating Text- Worlds in The Handmaid's Tale}

\author{
Raphael Marco Oliveira Carneiro*
}

\begin{abstract}
Ariel Novodvorski*
Resumo: Em vista da escassez de estudos interlinguísticos sobre a construção de mundos textuais, este artigo tem como objetivo analisar as representações mentais projetadas por elementos lexicogramaticais em um excerto do romance The Handmaid's Tale e nos fragmentos correspondes de duas traduções brasileiras. Com base em uma abordagem teórico-metodológica que integra Estilística, Estudos da Tradução e Teoria de Mundos Textuais, conclui-se que a tradução pode exercer efeitos na construção de mundos textuais por meio de escolhas tradutórias. Escolhas em relação ao aspecto verbal, processos verbais, aos objetos do mundo textual, à modalidade epistêmica podem impactar o modo como os textos são cognitivamente processados pelo leitor.
\end{abstract}

Palavras-chave: Teoria de Mundos Textuais; The Handmaid's Tale; Tradução Literária.

Abstract: Given the paucity of interlinguistic studies on world-building, this article analyses the mental representations projected by lexicogrammatical elements in an excerpt from the novel The Handmaid's Tale and in the corresponding fragments of two Brazilian translations. Based on a theoretical and methodological framework which consists of Stylistics, Text World Theory and Translation Studies, it is concluded that translating can exert an effect on world-building through translational choices. Choices in verbal aspect, verbal processes, text-world objects, epistemic modality can impact on the way texts are cognitively processed by readers.

Keywords: Text World Theory; The Handmaid's Tale; Literary Translation.

\footnotetext{
* Doutorando em Linguística e Linguística Aplicada pelo Programa de Pós-Graduação em Estudos Linguísticos no âmbito do Instituto de Letras e Linguística da Universidade Federal de Uberlândia, Uberlândia, MG, Brasil. ORCID: https://orcid.org/0000-0001-7577-4631. Email: raphael.olic@gmail.com ** Doutor em Estudos Linguísticos (UFMG) com pós-doutorado pela UFRGS. Docente do Programa de Pós-Graduação em Estudos Linguísticos. Professor Associado do Instituto de Letras e Linguística da Universidade Federal de Uberlândia, Uberlândia, MG, Brasil. ORCID: https://orcid.org/0000-0003-13708334. Email: arivorski@ufu.br
} 


\section{Introdução}

Mundos textuais são representações mentais resultantes do processamento cognitivo do discurso. Trata-se de um conceito que integra a Teoria de Mundos Textuais (WERTH 1999; GaVINS 2007), que vem sendo desenvolvida principalmente no âmbito da Estilística (LEECH; SHORT 2007; JefFrIES; MCINTYRE 2010). Estudos monolíngues são comuns dentro dessa teoria (Whiteley 2011; NUtTAL 2014; CanNing 2017), mas há uma escassez de estudos interlinguísticos, Lugea (2016) sendo uma exceção. Por isso, neste artigo, relatamos um estudo exploratório que tem como objetivo descrever a construção de mundos textuais em inglês e português, por meio da análise de estilo de um excerto do romance The Handmaid's Tale (1985), de Margaret Atwood, em comparação à tradução A História da Aia (1987), de Márcia Serra, e à retradução $O$ Conto da Aia (2006), de Ana Deiró. ${ }^{1}$

Esperamos que este estudo de caso possa contribuir para a comparação interlinguística de mundos textuais em textos literários em relação de tradução e retradução ${ }^{2}$ em inglês e português. Buscamos evidenciar, de modo amplo, como diferentes escolhas linguísticas atuam na produção de efeitos distintos, isto é, como escolhas linguísticas configuram estilos que influenciam o processamento cognitivo do discurso. De modo mais específico, buscamos compreender como textos literários ficcionais atuam na projeção de mundos textuais e o efeito que a tradução pode exercer na projeção desses mundos.

A seguir, abordamos conceitos fundamentais da Teoria de Mundos Textuais, bem como exploramos a relação entre cognição, estilo e tradução para, na sequência, analisar um excerto do romance com base nesses conceitos.

\section{Teoria de Mundos Textuais}

\footnotetext{
10 estudo no presente artigo integra pesquisa de doutorado financiada pela Coordenação de Aperfeiçoamento de Pessoal de Nível Superior - CAPES - Código 001. Agradecemos pelos pareceres e sugestões de revisão.

${ }^{2}$ Retradução é "toda tradução feita após a primeira tradução de uma obra [...]." No original: Toute traduction faite après la première traduction d'une œuvre [...]" (BERMAN, 1990, p. 1). (Todas as traduções de citações diretas são de nossa autoria).
} 
A Teoria de Mundos Textuais (WERTH 1999; GAVINS 2007) é um modelo linguístico-cognitivo do processamento discursivo humano, isto é, ela busca explicar como a mente humana representa o discurso. As suas bases teóricas remontam a um número diverso de disciplinas, incluindo Teoria de Mundos Possíveis, Psicologia Cognitiva, Linguística Cognitiva e Estilística. A premissa básica da Teoria de Mundos Textuais é que seres humanos processam e compreendem toda manifestação discursiva por meio da construção de representações mentais. Na base da teoria está a metáfora conceptual (LAKOFF; JOHNSON 1980) de que UM TEXTO É UM MUNDO. Entende-se que, ao produzir um texto projeta-se um mundo textual, uma representação mental que, por sua vez, é construído pelo processamento cognitivo do leitor/ouvinte. 0 objetivo da Teoria de Mundos Textuais (TMT) é fornecer conceitos analíticos para o exame sistemático dessas representações mentais, ou mundos textuais. Em outras palavras, a teoria fornece um aparato analítico que auxilia na descrição de como a mente humana representa conceptualmente os mais diversos tipos de textos. Assim, a TMT é conhecida como uma abordagem para a análise do discurso baseada em mundos.

A fim de traçar uma visão geral da TMT, podemos dizer que ela parte de uma concepção específica de linguagem e de participação no discurso. A linguagem é compreendida como um fenômeno cognitivo e experiencial, isto é, a produção e a recepção discursivas decorrem de representações mentais resultantes da conceptualização de eventos e experiências humanas. Assim, o evento comunicativo como um todo é de relevância, incluindo não só o texto enquanto produto enunciado, mas o discurso e seus participantes também, com conhecimentos e experiências que os constituem. Além disso, a projeção de mundos textuais no discurso enseja diversos aspectos relacionados, a saber: às cenas projetadas; aos processos (grupos verbais) que avançam o discurso; às fronteiras ontológicas entre os mundos; às percepções e atitudes expressas por actantes em relação às proposições do discurso; às relações de certeza, incerteza, hipoteticidade em relação ao que é dito; às relações entre actantes e focalização da narrativa; e à visão dupla engendrada no uso de metáforas. 
A concepção de linguagem como construtora de mundos é depreendida da Teoria de Mundos Possíveis (RYAN 1991), sendo de grande interesse para a análise do discurso literário, caracterizado pela imaginação criadora. 0 mundo real é compreendido como o mundo do discurso, o mundo em que participantes de carne e osso engajam em eventos comunicativos voluntariamente, seja na comunicação face-a-face ou no ato da leitura. Assim, o mundo real não é o único possível. A partir do mundo do discurso produz-se um mundo textual que, pelo próprio fato de se fazer como texto, é ontologicamente distinto do mundo do discurso. Dentro de um mesmo mundo textual outros mundos encaixados contribuem para a expansão da arquitetura ontológica do discurso.

A TMT está fundamentada no potencial da linguagem de construir mundos. A construção de mundos é vista como uma propriedade inerente à linguagem (GAVINS; LAHEY 2016). Dela decorre o entendimento de que há uma pluralidade de mundos, semioticamente construídos na comunicação humana. Dessa forma, a linguagem é compreendida como um sistema ontológico, capaz de se referir e criar relações de acessibilidade entre mundos. De acordo com o princípio de distanciamento mínimo (RYAN 1991), os leitores pressupõem que o mundo do texto seja similar ao mundo real, a menos que o contrário seja sugerido. Assim, um mundo textual pode ser mais ou menos próximo do mundo real. A (não) acessibilidade à (não) veracidade do conteúdo dos mundos textuais é dependente do estatuto ontológico de participantes e actantes (entidades textuais de um mundo textual).

Semino (2014: 1) compreende que "quando lemos inferimos ativamente um mundo textual por 'detrás' do texto". Ela define mundo textual como o "[...] contexto, cenário, ou tipo de realidade que é evocado em nossas mentes durante a leitura e que (concluímos) é referido pelo texto" (SEMINO 2014: 1). ${ }^{3}$ A construção de mundos é textualmente direcionada, ou seja, a materialidade textual fornece pistas linguísticas, que viabilizam a construção inferencial, por seres humanos, de modelos conceptuais da realidade ou de

\footnotetext{
${ }^{3}$ No original: When we read, we actively infer a text world 'behind' the text. By 'text world' I mean the context, scenario or type of reality that is evoked in our minds during reading and that (we conclude) is referred to by the text.
} 
realidades alternativas.

A ideia de um mundo textual pressupõe que o leitor constrói, na imaginação, um conjunto de objetos, independentes da linguagem, usando como guia proposições linguísticas, mas construindo essa imagem sempre incompleta em uma representação mais vívida por meio da informação fornecida por experiências da vida real ou derivada de outros textos. [...] diria que o conceito de mundo textual está associado com a faculdade de simulação mental. Para o texto construir um mundo, ou fragmentos de um mundo, ele deve oferecer algo para ver (ou ouvir, ou sentir) para os sentidos da mente (RYAN 1998: 139). ${ }^{4}$

Em outras palavras, um mundo textual existe a partir da combinação de informações fornecidas pelo texto e de informações fornecidas pela experiência, direta e vicária, textual e corpórea de seres humanos. Somente por meio dessa combinação é que indivíduos conseguem simular mentalmente outra realidade. A junção entre discurso e mente, entendida como cognição corporificada, permite a conceptualização de eventos e realidades, do nosso ponto de vista, essencial para a comunicação, seja ela literária ou não.

De acordo com Werth (1999: 20), “um mundo textual é um espaço dêitico, definido inicialmente pelo discurso em si, e especificamente pelos elementos dêiticos e referenciais contidos nele". 5 Em outras palavras, coordenadas dêiticas instauram um mundo textual no tempo e no espaço ao mesmo tempo em que permitem aos participantes se situarem no tempo e no espaço em relação ao discurso em pauta. A manipulação dessas coordenadas no discurso resulta em mudanças que instanciam outros mundos ou submundos, levando o leitor a conceptualizar uma multiplicidade de mundos textuais no curso da leitura. Esses mundos são produzidos e processados a partir de elementos construtores de mundo (tempo, espaço, objetos, actantes) e de proposições funcionais, que atuam no desenvolvimento do discurso. De forma mais detalhada, a dêixis pessoal e espaço-temporal são

\footnotetext{
4 No original: The idea of textual world presupposes that the reader constructs in imagination a set of language-independent objects, using as a guide the textual declarations, but building this always incomplete image into a more vivid representation through the import of information provided by real-life experience or derived from other texts. [...] I would say that the concept of textual world is associated with a faculty of mental simulation. For the text to construct a world, or fragments of a world, it must offer something to see (or hear, or feel) to the senses of the mind.

${ }^{5}$ No original: A text world is a deictic space, defined initially by the discourse itself, and specifically by the deictic and referential elements in it.
} 
responsáveis por situar um mundo textual e fundar o seu posicionamento em relação aos participantes do discurso, podendo ser mais próximo ou mais remoto desses participantes. As proposições funcionais, analisadas com base no sistema de transitividade da Gramática Sistêmico-Funcional (HallidaY; MATTHIESSEN 2014), contribuem para o desenvolvimento e avanço da narrativa. Aplicações recentes da TMT baseadas na Gramática Cognitiva (LANGACKER 2008) também têm sido desenvolvidas (HARRISON; ET AL. 2014). Enquanto os elementos construtores estabelecem os parâmetros básicos de construção do mundo textual, as proposições funcionais atuam no desenvolvimento de ações e estados das entidades do mundo textual.

Um dado texto dificilmente projeta apenas um mundo textual, de modo que a projeção de submundos, conforme a terminologia de Werth (1999), ou transições entre mundos, world-switches na terminologia de Gavins (2007), são frequentes. Essas transições podem ser instanciadas por mudanças no tempo e aspecto verbais, bem como por expressões temporais e advérbios. Além disso, transições entre mundos também são instanciadas por verbos modais, os quais são analisados com base na gramática modal de Simpson (1993). As modalidades são classificadas como bulomaica, deôntica, epistêmica e perceptual. Cada uma expressa, respectivamente, desejos, obrigações, crenças e percepções. Uma vez que as diferentes modalidades expressam atitudes em relação às proposições do discurso, o efeito delas é o de relativizar ou criar um distanciamento em relação ao que seria uma proposição categórica. Por isso, entende-se que o uso de verbos modais e expressões modais torna-se um gatilho para a projeção de mundos modais, não atualizados no mundo textual matriz; por isso, mundos modais implicam cenários mais remotos. No Quadro 1, com exemplos prototípicos de verbos e expressões modais, vemos, por exemplo, como o advérbio evidently, apesar de enfatizar a proposição 'estar certo', na verdade a relativiza, condicionando-a a uma evidência, enquanto a proposição categórica 'você está certo' é epistemicamente mais forte. Da mesma forma, os usos de wish, must e may, relativizam ou condicionam a proposição categórica em relação a um desejo, obrigação e possibilidade, respectivamente. 
Quadro 1: Sistemas modais em inglês

\begin{tabular}{|c|c|}
\hline Sistema modal & Exemplos \\
\hline Bulomaico & I wish you'd leave. (Queria que você saísse) \\
\hline Deôntico & You must leave. (Você deve sair) \\
\hline Epistêmico & You may be right. (Você pode estar certo) \\
\hline Perceptual (subsistema modal epistêmico) & $\begin{array}{c}\text { You're evidently right. (Você está } \\
\text { evidentemente certo) }\end{array}$ \\
\hline
\end{tabular}

Fonte: elaborado com base em Simpson (1993).

Transições entre mundos também são instanciadas no uso de metáforas, projetando, assim, mundos mesclados (blended worlds), resultados da conceptualização combinada de mundos textuais independentes. Apesar de mundos mesclados existirem no mesmo nível conceptual que outros mundos textuais e possuírem estrutura própria, com elementos construtores de mundos e proposições funcionais, eles mantêm uma conexão direta com o mundo que thes deu origem; por isso a bidirecionalidade das setas na Figura 1. Mundos mesclados surgem geralmente a partir da integração conceptual entre domínios, um abstrato e outro concreto. Por exemplo, na metáfora conceptual A VIDA É UM TEATRO temos a integração conceptual de dois domínios em que 'vida', o elemento abstrato, é mesclado às características e à experiência de vivenciar um 'teatro'.

A Figura 1 apresenta em forma de diagrama, comumente usado para a visualização de mundos textuais, a tipologia básica de mundos passíveis de serem engendrados na comunicação humana.

Figura 1: Tipologia simplificada da Teoria de Mundos Textuais. 


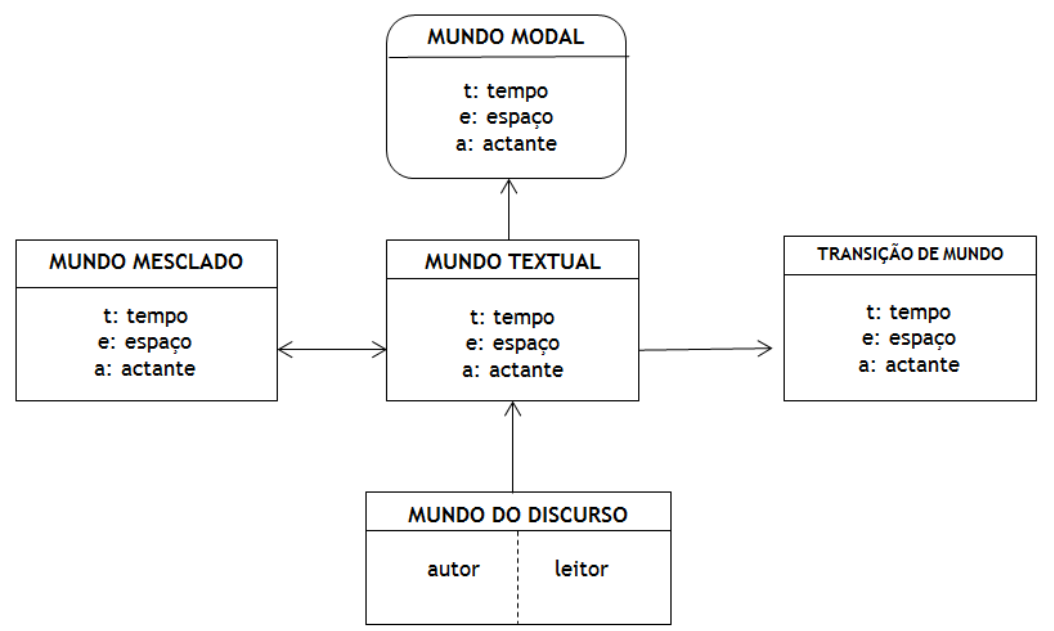

Fonte: traduzido a partir de Gavins, 2018.

A Figura 1 ilustra como diferentes mundos se originam a partir do mundo do discurso. 0 mundo do discurso é o mundo imediato da produção e recepção de discursos. No caso da comunicação literária escrita é descrito como dividido (split), isto é, autor e leitor não partilham das mesmas coordenadas espaço-temporais na produção e recepção de um texto. Leitores frequentemente habitam espaços e tempos muito diferentes daqueles em que um texto escrito é inicialmente produzido. Esse mundo do discurso dividido faz com que um texto possa ser compreendido de modos diferentes em tempos e locais diferentes. Isso se deve principalmente a diferenças entre os participantes e seus conjuntos de conhecimento, que se modificam ao longo do tempo. Esses conhecimentos, experienciais, culturais, linguísticos e perceptuais, são postos em uso na comunicação, por meio de processos inferenciais, que contribuem para a construção mais ou menos detalhada de mundos textuais.

Um dado texto produzido no mundo do discurso projeta um mundo textual matriz que pode projetar outros mundos por meio de transições espaço-temporais (world-switch), modalidade (modal world) e metáforas (blended world). Os mundos mesclados produzidos pelo uso de metáforas apresentam dupla direcionalidade, uma vez que ocupam uma posição conceptual que mescla elementos do mundo textual matriz em um mundo textual concomitante, partilhando características de dois mundos em uma mescla conceptual (FAUCONNIER; TURNER 2002). 
O entendimento de que textos projetam mundos tem implicações para o modo como efeitos diversos podem ser obtidos a partir da construção desses mundos. A construção de pontos de vista, empatia, emoção, resistência, dentre outros fenômenos, pode ser explicada por meio da natureza encaixada de vários mundos textuais engendrados em dado discurso (cf. GAVINS 2007).

No que concerne à relação entre o mundo do discurso e o mundo textual, por meio da comunicação escrita, a presença dos participantes, autor e leitor, assim como do elemento texto, é indispensável, conforme explicação de Werth (2002):

[...] o(a) autor(a) cria apenas um texto; ele/ela terá um mundo textual específico em mente, mas não há garantia nenhuma de que o leitor conseguirá produzir o mesmo mundo textual quando da leitura desse texto. Não podemos dizer que o mundo textual do autor é o mundo definitivo, já que, de fato, não existe tal coisa. Podemos dizer, portanto, que um mundo textual não passa a existir até que cada um dos três elementos - autor, texto e leitor - estejam presentes. (WERTH 2002: 189) ${ }^{6}$

No caso de textos traduzidos há um terceiro participante no mundo do discurso que precisa ser considerado, o tradutor. Sem esse participante, um mundo textual pode deixar de existir para leitores da cultura de chegada. Esse aspecto parece estar ausente nas formulações teóricas de Werth (1999) e Gavins (2007), tornando-se relevante considerar as influências que esse participante pode exercer na projeção de mundos textuais. Dessa forma, na seção seguinte, introduzimos noções em torno da relação estilo, tradução e mundos textuais.

\section{Cognição, Estilo e Tradução}

A relação que estabelecemos entre cognição, estilo e tradução está fundamentada nos conceitos apresentados por Boase-Beier (2014), que aborda

\footnotetext{
${ }^{6}$ No original: [...] the author creates only a text; he/she will have a particular text world in mind, but there is no guarantee at all that the reader will manage to reproduce the same text world on reading that text. We cannot say that the author's text world is the definitive one, since, in fact, there is no such thing. We may say, therefore, that a text world does not come into being until each of the three elements-author, text and reader-are present.
} 
estilo como uma entidade linguística e cognitiva, e o define da seguinte maneira:

[...] em termos linguísticos, estilo expressa o que está além da semântica [...] em termos cognitivos, reflete uma série de escolhas, determinadas em parte por um estado cognitivo que absorveu influências históricas, sociológicas e culturais. Esse estado da mente é atribuído por um leitor a um personagem, narrador, ou ao autor (BOASE-BEIER 2014: 147). ${ }^{7}$

O estado cognitivo mencionado está atrelado à ideia de que o processo tradutório envolve a tradução da mente presente no texto e que a mente é constituída por características históricas, sociais e culturais. Decorre dessa concepção que “[...] a tradução de um texto literário é a tradução de um estado cognitivo particular corporificado no texto" (BOASE-BEIER 2014: 114). ${ }^{8}$ Em outras palavras, escolhas linguísticas, bem como a tradução interlinguística dessas escolhas, são vistas como construtoras de um estado mental, seja do narrador, seja de personagens, que influencia o leitor. A depender das escolhas feitas pelo tradutor, esse estado mental pode sofrer mudanças e deixar de exercer influência no leitor ou ter outro tipo de efeito.

Boase-Beier (2014) atesta a existência de uma virada cognitiva nos Estudos da Tradução e aponta abordagens cognitivas, em especial, a Estilística Cognitiva (SEMINO; CULPEPER 2002; STOCKWELL 2002), que abriga a TMT, como promissoras no "[...] fornecimento de descobertas sobre a natureza e os efeitos da diferença” (BOASE-BEIER 2014: 72). ${ }^{9}$ Além disso, a concepção de leitor ativo, em oposição a passivo, no processo da leitura, que perpassa a Estilística Cognitiva, nos auxilia a conceber o tradutor como “[...] um participante ativo na leitura do texto-fonte" (BOASE-BEIER 2014: 73). ${ }^{10}$ Com base na ideia de que o discurso literário gera efeitos na mente, renovando ou

\footnotetext{
7 No original: [...] linguistically speaking, style expresses what is beyond semantics, so, cognitively speaking, it reflects a series of choices, determined in part by a cognitive state which has absorbed historical, sociological and cultural influences. This state of mind is attributed by a reader to a character, narrator, or to the author.

${ }^{8}$ No original: [...] the translation of a literary text is the translation of a particular cognitive state as it has become embodied in the text.

${ }^{9}$ No original: So cognitive approaches are attractive not least because they promise help in providing insights into the nature and effects of the difference.

${ }^{10}$ No original: The translator can now be shown to be an active participant in the reading of the source text.
} 
mudando nossas representações mentais do mundo, Boase-Beier (2014) sugere uma abordagem tradutória,

[...] na qual o estilo do texto transmite e cria um estado cognitivo. Se a tradução deixa de capturar esse estado cognitivo, o texto-alvo terá menos efeito nas mentes dos leitores. Assim, um primeiro passo para preservar o efeito mental transformador da literatura, na tradução, será reconhecê-lo. (BOASE-BEIER 2014: 77) $)^{11}$

Em síntese, como leitor ativo do texto-fonte, a tarefa do tradutor reside em reconhecer o estado cognitivo evocado pelo texto e recriá-lo na tradução. Entendemos que a recriação desse estado cognitivo envolve a projeção de mundos textuais.

Essa visão cognitiva da tradução e de que um texto está correlacionado à mente, contribui para o entendimento da importância que percepções, atitudes e posicionamentos assumem na leitura de um texto literário traduzido. O reconhecimento de traços estilísticos, como ambiguidade, contrastes, metáfora, mudança de perspectiva, torna-se preponderante para o tradutor literário. Assim, entendemos que a projeção de mundos textuais, incluindo as transições para mundos modais, mundos mesclados, dentre outras transições, são relevantes para a expressão desses traços.

\section{Mundos textuais em The Handmaid's Tale}

Margaret Atwood (1939-), escritora canadense de narrativas curtas, romances, poemas, crítica literária, teve suas obras introduzidas no sistema literário brasileiro, via tradução, pela Editora Marco Zero nos anos de 1980 e 1990. Desde então, outras editoras também se ocuparam da tradução de suas obras, como Companhia das Letras, Globo e Morro Branco, tendo vários de seus livros traduzidos no Brasil (cf. CARNEIRO, no prelo). Os seis romances publicados pela Marco Zero foram retraduzidos, no século XXI, e publicados

\footnotetext{
${ }^{11}$ No original: For translation this suggests an approach in which the style of the text both conveys and creates a cognitive state. If the translation fails to capture such a cognitive state the target text will have less effect on its readers' minds. So a first step towards preserving the mind-altering effect of literature in translation will be to recognize it.
} 
pela editora Rocco (CARNEIRO; NovodvorSKI 2020). Dentre eles, o romance The Handmaid's Tale (1985) conta com duas traduções, A História da Aia (1987), traduzido por Márcia Serra e O Conto da Aia (2006), por Ana Deiró. É com base em um excerto desses três textos que desenvolvemos a análise exploratória na sequência.

No mundo do discurso, The Handmaid's Tale apresenta dois participantes: a autora Margaret Atwood e um leitor específico, separados pelo tempo e pelo espaço. No caso das traduções, o mundo do discurso engloba as tradutoras também, Márcia Serra e Ana Deiró. ${ }^{12} 0$ romance começa com narração em primeira pessoa do plural; passando, mais adiante, ao uso da primeira pessoa do singular também. Nesse início, o leitor desconhece qual é o personagem-narrador da história. Descobre-se nos capítulos seguintes que se trata de uma mulher, uma aia da República de Gilead, cuja função é servir reprodutivamente ao seu Comandante. Entende-se também que o primeiro capítulo é na verdade um flashback, ou seja, um mundo textual mais remoto em relação ao presente em que a narradora se encontra. Por razões de simplificação, trataremos desse flashback como mundo textual matriz.

Trata-se de uma narradora intradiegética que inicia a narrativa ancorando-a no passado, no que havia sido o ginásio. Não se dá a conhecer o local e o tempo de onde a história está sendo contada nesse momento. Por meio dos grupos verbais slept e had been, o período inicial estabelece, ao mesmo tempo, um mundo textual e uma transição temporal de mundos para um mundo anterior ao passado. Dito de outro modo, o leitor é levado a representar mentalmente, logo de início, dois mundos textuais, um em que 'nós dormíamos no que havia sido o ginásio', ou seja, um em que o ginásio não existe mais, e outro em que ele existia com todas as suas funcionalidades esportivas. O efeito inicial dessa transição de mundos é tematicamente significativo para o romance como um todo, visto que a narrativa se constrói na mudança de um estado de coisas para outro, ou seja, o regime teocrático autoritário que se instaura na sociedade representada no romance altera o

\footnotetext{
12 Está além do escopo deste artigo discorrer em mais detalhes sobre o mundo do discurso instaurado a partir da leitura do romance. Nosso foco de análise reside no nível do mundo textual.
} 
mundo anterior.

Os conhecimentos experienciais do mundo do discurso do leitor sobre ginásios esportivos desempenham um papel cognitivo de relevância, no modo como esse parágrafo inicial é recriado mentalmente na leitura. A depender dessas experiências, a representação mental do fragmento pode ser mais ou menos vívida, imersiva, mais ou menos significativa para cada leitor.

A seguir, apresentamos o trecho do texto-fonte com a identificação dos elementos construtores de mundos, das proposições funcionais e das transições de mundos em diagrama na Figura 2.

(1) We slept in what had once been the gymnasium. (2) The floor was of varnished wood, with stripes and circles painted on it, for the games that were formerly played there; the hoops for the basketball nets were still in place, though the nets were gone. (3) A balcony ran around the room, for the spectators, and I thought I could smell, faintly like an afterimage, the pungent scent of sweat shot through with the sweet taint of chewing gum and perfume from the watching girls, felt-skirted as I knew from pictures, later in miniskirts, then pants, then in one earring, spiky greenstreaked hair. (4) Dances would have been held there; the music lingered, a palimpsest of unheard sound, style upon style, an undercurrent of drums, a forlorn wail, garlands made of tissue-paper flowers, cardboard devils, a revolving ball of mirrors, powdering the dancers with a snow of light (ATWOOD 1998: 3; períodos numerados e grupos verbais sublinhados por nós).

Figura 2: Diagrama de mundos textuais em The Handmaid's Tale 


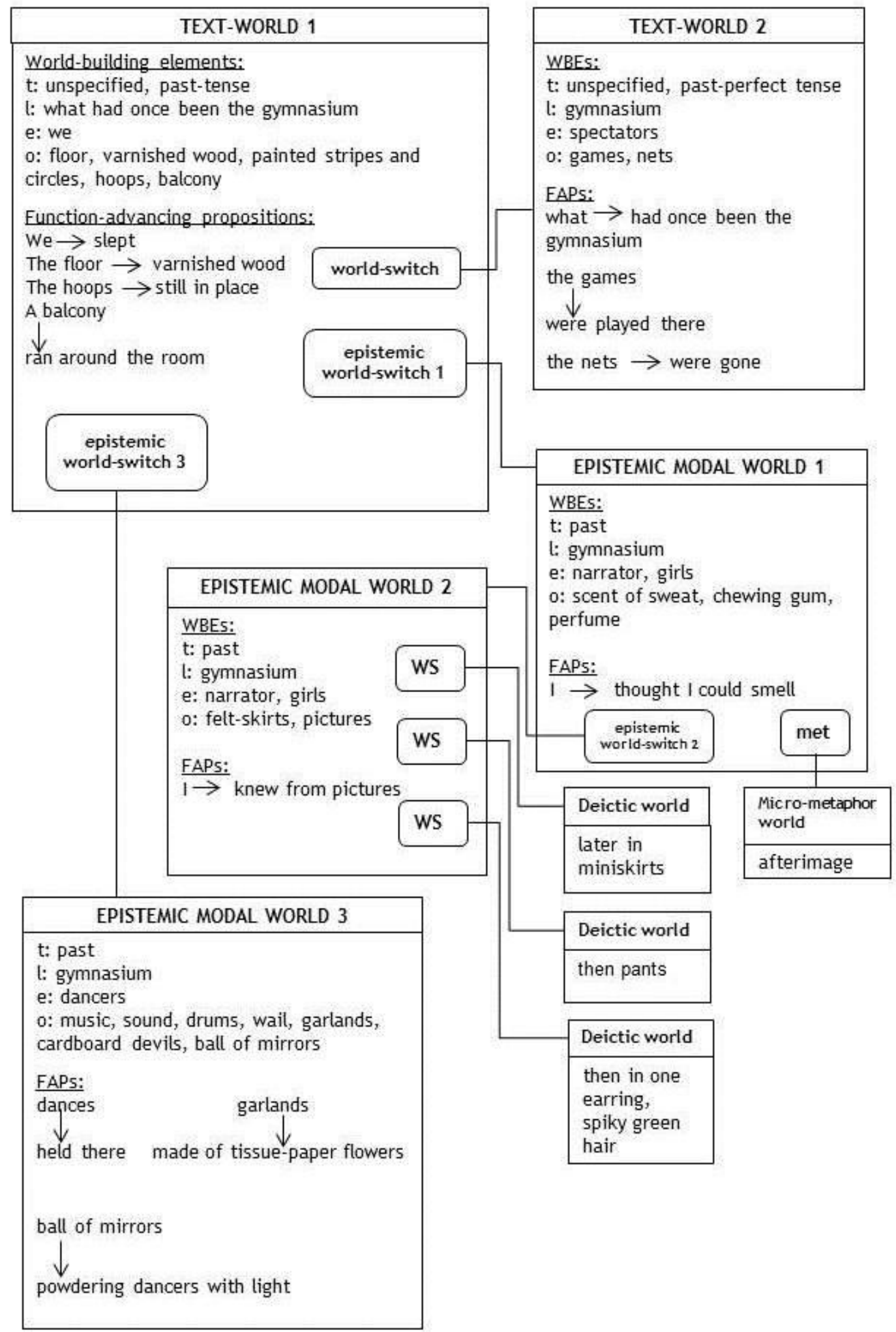

Fonte: elaborado pelos autores.

Para além da transição mencionada, há também a transição para mundos modais epistêmicos. O primeiro deles se refere à percepção olfativa da narradora, que pensa poder sentir os cheiros que antes pairavam no 
ginásio. 0 segundo, encaixado no primeiro, é resultante do conhecimento da narradora-personagem em relação ao que viu em fotografias que retratavam a moda feminina de períodos anteriores. Três transições dêiticas estão encaixadas nesse segundo mundo epistêmico. Os três mundos dêiticos levam o leitor a visualizar sequencialmente as mudanças da moda em três épocas distintas. Cada item da moda mencionado tem as suas próprias coordenadas espaço-temporais e, por isso, instanciam mundos diferentes. 0 terceiro mundo epistêmico contribui para recriar memórias da narradora quanto a uma cena de baile que teria acontecido no ginásio. Há predominância de processos relacionais e mentais (indicados na Figura 2 pelas setas na posição horizontal; setas na posição vertical indicam processos materiais) que atuam na descrição do espaço e das percepções da narradora, isto é, poucos eventos acontecem na passagem selecionada. (No Quadro 2, no final das análises, apresentamos uma classificação dos processos).

A estruturação da cena é realizada por meio do processo de escaneamento sequencial (sequential scanning) (LANGACKER 2008). A descrição do ginásio em (2) e (3) é construída por meio da composição espacial em uma sequência de objetos 'the floor', 'the hoops,' 'a balcony'. Essa sequência também segue uma direcionalidade, de baixo para cima, de modo que o leitor é levado a processar o texto e a mentalmente visualizar uma sequência de objetos, que vai de um foco mais fechado, restrito, o chão, a uma visão mais ampla do espaço que circunda todo o ginásio, a arquibancada, realizando assim o que Langacker (2008: 81) chama de 'zooming out'. A sequência cumulativa de objetos resulta em uma conceptualização global do espaço, que se estabelece pelo processamento individual dos objetos, que coexistem em um mesmo espaço, resultando em um escaneamento sumário (summary scanning) também.

Em (3), a sequência de sintagmas separados por vírgula e iniciados com advérbios de tempo, estabelece uma sequência temporal de objetos que leva o leitor a visualizar as roupas e acessórios que as mulheres usavam de acordo com a moda de diferentes épocas. Os advérbios 'later' e 'then' instanciam três transições de mundo, encaixadas no mundo epistêmico da narradora. Cada sintagma estabelece um foco de atenção pelo escaneamento sequencial, 
mas que não se acumulam em um todo unificado já que cada sintagma seria referente a um tempo diferente e não coexistiriam no mesmo espaço-tempo. Em (4) o mesmo processo de escaneamento ocorre, com a separação de sintagmas por vírgulas. Cada sintagma atrai a atenção do leitor e o leva a representar mentalmente cada um dos sons e objetos que compõem a cena de baile rememorada pela narradora. A oração final convida o leitor a focar na estranha conceptualização, de dançarinos sob a neve, ainda que metaforicamente, como alvo final do escaneamento.

No parágrafo de abertura do romance, os posicionamentos dêiticos temporal, espacial e pessoal do mundo textual são instaurados. A narradora apresenta suas percepções, mas também fala em nome de uma coletividade (we), que se encontra em um espaço-tempo diferente do que existia anteriormente. As transições projetadas entre os mundos nesse parágrafo funcionam como um tipo de estratégia que apresenta um mundo textual como mais próximo do centro dêitico (we,l) e outros mundos mais distantes desse centro. Esses mundos distantes pertencem a um domínio de existência remoto, que existe apenas na mente da actante, e não tratam das circunstâncias atuais em que ela se encontra. Cria-se, portanto, uma arquitetura ontológica, na qual um mundo, o mais próximo do centro dêitico, é mais real do que os outros, que são mais remotos, principalmente por se constituírem de memórias. Em termos de acessibilidade, tanto o mundo textual matriz quanto os mundos modais são acessíveis apenas à actante. Já que a actante-narradora, enquanto entidade de um mundo textual, existe em um plano ontológico distinto do mundo do discurso dos participantes (leitores), os participantes processam o mundo textual como acessível ao actante apenas. Em outras palavras, o leitor não pode verificar a veracidade do que é narrado por não poder experienciar os mundos evocados diretamente.

Os três mundos epistêmicos, ao serem povoados por entidades que existem apenas na mente da narradora, contêm uma riqueza maior de objetos do que a matriz do mundo textual que, em comparação, é pobre e destituída dos cheiros, luminosidade, sons, eventos e diversidade dos submundos. Os mundos modais epistêmicos projetados pela narradora são descritos em 
riqueza de detalhes e, por isso, parecem ser mais vívidos e vibrantes do que a matriz do mundo textual em que ela se encontra, o que transparece certa nostalgia, sentida pela narradora, em relação aos tempos que se foram. 0 sentimento nostálgico pode ser inferido a partir de escolhas lexicais, como once (outrora), formerly (antigamente), gone (sumido, desaparecido), faintly (tênue, ligeiramente), forlorn wail (lamento plangente, lamento desesperançado), snow (nevasca, neve), que contribuem cumulativamente para a evocação de uma atmosfera gélida e triste. De fato, toda essa construção textual apresenta relevância temática para o romance, que trata diretamente de questões relacionadas a mudanças que podem ocorrer na sociedade e alterar o mundo em que se vive. Os mundos modais contribuem para o entendimento do leitor de que há algo de estranho, de anormal, no mundo ficcional, introduzindo, assim, a atmosfera distópica do romance. Essa análise complementa e corrobora a afirmação de Nuttall (2014), de que é nos mundos modais e nas transições dêiticas que o enriquecimento da conceptualização geral em The Handmaid's Tale acontece. "Tais mundos encaixados geralmente contêm informações essenciais para a caracterização dessa narradora e para a nossa apreensão da sociedade distópica, na qual suas circunstâncias imediatas [...] estão situadas" (NUTTALL 2014: 93). ${ }^{13}$

$\mathrm{Na}$ sequência, apresentamos o mesmo parágrafo analisado anteriormente em suas versões traduzidas.

(1) Dormíamos no que havia sido o ginásio. (2) 0 assoalho era de madeira envernizada, com listras e círculos pintados para os jogos de antigamente. (3) Os aros das cestas de basquete ainda estavam no lugar, embora as redes tivessem sumido. (4) Uma galeria para espectadores contornava o recinto, e parecia-me poder sentir, tênue como uma pós-imagem, o cheiro pungente de suor, impregnado do aroma doce de chiclete e do perfume das garotas da assistência, com suas saias de feltro, que eu conhecia das fotografias; mais tarde, com suas mini-saias; depois, suas calças; depois, com seus brincos em uma só orelha e seus cabelos espetados, pintados com mechas verdes. (5) Na certa, ali havia bailes, antigamente; a música ainda pairava no ar, um palimpsesto de sons inaudíveis, estilos sobrepostos em camadas, uma corrente profunda de ritmo, um lamento plangente, grinaldas de flores de papel crepom, diabos de papelão, uma bola giratória espelhada, salpicando os pares na pista com uma nevasca de luz (ATWOOD 1987: 9; períodos numerados e grupos verbais sublinhados por nós).

13 No original: Such embedded worlds often contain information central to the characterisation of this narrator and to our comprehension of the wider dystopian society in which her immediate circumstances [...] are situated. 
(1) Nós dormimos no que outrora havia sido o ginásio esportivo. (2) 0 assoalho era de madeira envernizada, com listras e círculos pintados, para os jogos que antigamente eram disputados ali; os aros para as redes das cestas de basquete ainda estavam em seus lugares, embora as redes tivessem desaparecido. (3) Uma arquibancada cercava o aposento para os espectadores, e imaginei que podia sentir, muito ligeiramente, como uma imagem evocada, o cheiro pungente de suor, mesclado com a doçura latente de goma de mascar e o perfume das garotas assistindo aos jogos vestidas com saias de feltro, como eu tinha visto em fotografias, mais tarde de minissaias, em seguida de calças, depois com um brinco só, os cabelos espetados com mechas pintadas de verde. (4) Bailes teriam sido realizados ali, um palimpsesto de sons jamais ouvidos, um estilo seguindo-se ao outro, como subcorrente, uma cadência de tambores, um lamento desesperançado, guirlandas feitas de flores de papel de seda, máscaras de cartolina, uma esfera giratória coberta de espelhos, salpicando os dançarinos com uma neve de luz (ATWOOD 2006: 11; períodos numerados e grupos verbais sublinhados por nós).

Considerando aspectos relacionados à forma, a tradução tem 5 períodos enquanto a retradução tem 4, assim como o texto-fonte. Enquanto a tradução tem 15 grupos verbais, a retradução tem 22, e o texto-fonte 16 . Em vista do aspecto energético, típico dos verbos (LANGACKER 2008: 104), a maior quantidade de grupos verbais e, consequentemente, de proposições funcionais na retradução, atribui maior dinamismo à conceptualização dos mundos textuais, gerando mais transferência de energia entre as entidades da retradução do que na tradução e no texto-fonte.

No primeiro período, observamos que, embora ambas as traduções usem o pretérito mais-que-perfeito composto na tradução do segundo grupo verbal, o primeiro verbo da tradução está no pretérito imperfeito e o da retradução no pretérito perfeito. Essa diferença de escolhas tradutórias implica no entendimento de que na tradução a ação de dormir é projetada como algo em progresso, ou um hábito passado. Já na retradução optou-se pelo pretérito perfeito, o que sugere que a ação foi concluída e que não se dorme mais lá, algo que ocorreu uma vez e não mais se repetiu. Essa escolha de tradução tem efeitos no modo como o primeiro período do texto é processado cognitivamente. Mesmo com essa diferença, a projeção de mundos textuais é semelhante ao original, o que difere é a representação temporal de uma mesma ação no passado.

Os mundos textuais projetados são semelhantes na comparação entre a tradução e a retradução, apesar dessas projeções serem realizadas por 
escolhas diferentes. 0 uso dos tempos pretérito imperfeito e perfeito e pretérito mais-que-perfeito composto projetam respectivamente o mundo textual matriz e a primeira transição de mundo. Os mundos modais epistêmicos são projetados por escolhas diferentes quanto aos processos e ao aspecto do pretérito. As escolhas na tradução foram 'parecia-me poder sentir,' e 'eu conhecia das fotografias', enquanto as escolhas da retradução foram 'imaginei que podia sentir,' e 'eu tinha visto em fotografias.' $\mathrm{Na}$ tradução, dois verbos estão no pretérito imperfeito 'parecia-me' e 'conhecia', enquanto na retradução, temos o pretérito perfeito 'imaginei' e o pretérito-mais-que-perfeito composto 'tinha visto', todos processos mentais. Essas diferenças formais acenam para diferenças de processamento do texto. A imperfectividade expressa pelas escolhas aspectuais na tradução leva ao processamento das proposições como referentes à duração das ações no passado. Já a perfectividade expressa pelas escolhas aspectuais na retradução leva ao processamento das proposições como referentes a algo concluído no passado. Adicionalmente, na retradução, a projeção do segundo mundo modal epistêmico se efetiva pelo verbo 'ver', ressaltando uma dimensão mais perceptual, enquanto na tradução utilizou-se 'conhecer', que destaca uma dimensão mais cognitiva da modalidade epistêmica.

A tradução fez mais uso do pretérito imperfeito. De fato, o pretérito imperfeito, dado seu caráter temporal, que expressa duração de eventos, de continuidade de ações, ganha relevância cognitiva no processamento do texto. Entendendo o contexto em que a narradora está rememorando, imaginando eventos, ao mesmo tempo em que descreve um espaço, relacionao a um passado recente, o aspecto imperfeito assume relevância, no modo como esse sentimento é processado pelo leitor. Apesar de a retradução recriar esse sentimento também, as ocorrências do pretérito perfeito ('dormimos', 'imaginei') e do pretérito mais-que-perfeito ('tinha visto') diminuem o efeito cumulativo que a imperfectividade atinge na tradução, sendo 8 usos (dormíamos, era, estavam, contornava, parecia-me, conhecia, havia, pairava) do imperfeito na tradução e 5 usos (era, eram, estavam, cercava, podia) do imperfeito na retradução. Essa conexão durativa entre passado e um passado mais recente é reforçada pelo mundo metafórico ('met' 
na Figura 2) engendrado a partir da figura de linguagem símile 'like an afterimage', traduzida 'como uma pós-imagem' e retraduzida 'como uma imagem evocada.' Temos o domínio abstrato 'passado' metaforizado no domínio concreto 'fotografia'. O uso desse símile contribui para a projeção de um mundo mesclado em que o leitor é levado a conceptualizar, em um espaço paralelo ao mundo modal, o efeito visual gerado por esse fenômeno da pósimagem, em que resquícios do que fora anteriormente visualizado permanece, após não mais existir; o leitor deve acionar conhecimentos perceptuais do campo visual para compreender a comparação em questão. Tem-se, portanto, a própria imperfectividade corporificada em uma expressão metafórica, licenciada pela metáfora conceptual que subjaz: PASSADO É UMA FOTOGRAFIA. Essa metáfora é reforçada nos mundos dêiticos encaixados referentes a fotografias de épocas diferentes.

O terceiro mundo modal epistêmico instanciado em 'dances would have been held there' e traduzido como 'na certa, ali havia bailes' e retraduzido como 'bailes teriam sido realizados ali' também revela escolhas diferentes na expressão da modalidade. A retradução apresenta escolhas mais próximas do texto-fonte em termos de ordem de palavras e tempo verbal, usando o futuro do pretérito composto, que expressa incerteza no dizer. A tradução, contudo, faz uso de uma expressão epistêmica 'na certa' combinada ao pretérito imperfeito, o que expressa maior certeza quanto ao dizer, em relação ao mesmo trecho retraduzido. Mesmo não sendo uma proposição categórica, a mesma proposição na tradução é, de maneira epistêmica, mais forte do que na retradução, ou seja, um pouco mais de certeza é expressado na fala da narradora da tradução. Enquanto a tradução usa um processo existencial 'havia', a retradução usa um processo material 'realizados', assim como o original 'held'. Essa análise revela que posicionamentos epistêmicos, como nesse exemplo, podem vir a ser expressos de modos diferentes entre as traduções, podendo gerar, cumulativamente, impressões diferentes nos leitores quanto ao ponto de vista ou perspectiva da narradora.

Em relação aos mundos dêiticos encaixados no segundo mundo modal, escolhas semelhantes foram feitas entre tradução e retradução ('mais tarde', 'depois', ‘depois'; 'mais tarde’, ‘em seguida', ‘depois', respectivamente). 0 
texto-fonte usa os advérbios 'later', 'then' e 'then', nessa sequência. A retradução optou por não repetir os advérbios como no texto-fonte, enquanto a tradução usou 'depois' duas vezes nas duas ocorrências de 'then' no textofonte. Cognitivamente o efeito dessas escolhas entre tradução e retradução é semelhante, os mesmos mundos dêiticos com a mesma sequência temporal são projetados.

A retradução apresenta elementos dêiticos que a tradução não possui. Por exemplo, enquanto a tradução optou por "para os jogos de antigamente", a retradução optou por "os jogos que antigamente eram disputados ali", enfatizando a localidade em que os jogos se realizavam pelo advérbio espacial/demonstrativo 'ali.' Em 'Bailes teriam sido realizados ali' mantém-se a ordem do texto-fonte "Dances would have been held there," enquanto a tradução opta por outra ordem "na certa, ali havia bailes." A retradução também opta por explicitar o pronome 'nós' no primeiro período do parágrafo, enquanto a tradução o omite.

Observa-se também que objetos do mundo textual recebem traduções diferentes que, potencialmente, influenciam a imaginação dos leitores. Enquanto o texto-fonte se refere a 'garlands made of tissue-paper flowers, cardboard devils', a tradução se refere a 'grinaldas de flores de papel crepom, diabos de papelão' e a retradução se refere a 'guirlandas feitas de flores de papel de seda, máscaras de cartolina'. Esses exemplos contêm objetos do mundo textual que influenciam em como a cena é mentalmente representada pelo leitor. 'Papel de seda' e 'papel crepom', assim como 'diabos de papelão' e 'máscaras de cartolina' são objetos essencialmente diferentes, que levam o leitor de cada tradução a uma representação diferente no momento da leitura. As diferentes escolhas para a tradução do item lexical 'garlands' também podem gerar diferentes representações mentais. 'Grinaldas' podem levar o leitor a ativar conhecimentos relacionados a casamento, enquanto 'guirlanda' pode gerar associações cognitivas a comemorações natalinas, mas de qualquer forma situações festivas. ${ }^{14} \mathrm{Em}$

\footnotetext{
${ }^{14}$ Uma busca avançada na Web, enquanto fonte de conhecimento semântico, considerando o idioma português, país Brasil e no último ano, sugere que as unidades lexicais 'grinalda' e 'guirlanda' estão comumente associadas aos domínios 'casamento' e 'natal', respectivamente.
} 
certa medida, portanto, essas divergências nas traduções apontam que a tradução pode exercer um papel na construção de mundos textuais, mesmo que em nível microtextual. Em outras palavras, a escolha ao traduzir dado objeto no mundo textual exerce influência nos conhecimentos ativados pelo leitor, levando-o a conceptualizar a cena em questão de um modo ou de outro.

À guisa de conclusão, a análise do primeiro parágrafo do romance revela alguns aspectos estilísticos com efeitos para o processamento cognitivo dos textos. O primeiro deles está relacionado à complexidade envolvida na construção e transição entre mundos textuais encaixados. Foi possível demonstrar a construção de mundos textuais e como as transições de mundos, sejam elas dêiticas, epistêmicas ou metafóricas, podem estar encaixadas em outros mundos. Em um único parágrafo, relativamente curto, o leitor é levado a conceptualizar cenários relativamente próximos e distantes do mundo do discurso, por meio dos elementos construtores de mundos, das proposições funcionais e de mundos encaixados. Além disso, foi possível observar que a tradução pode exercer efeitos na construção desses mundos por meio das escolhas tradutórias. Escolhas em relação ao aspecto verbal, a diferentes processos verbais, aos objetos do mundo textual, à modalidade epistêmica, podem impactar o modo como os textos são cognitivamente processados.

Em termos estilísticos, o uso do aspecto imperfectivo mostrou-se relevante para a tradução do estado cognitivo, expresso nesse primeiro parágrafo. Esse estado cognitivo refere-se ao estado mental projetado pelo texto, ou seja, de uma mente que parece sentir nostalgia por um estado de coisas passadas que não existe mais, mas que não deixa de se fazer sentido e presente, ainda que fugidiamente, para a narradora-actante. A combinação de escolhas lexicogramaticais com as inferências geradas por essas escolhas contribui para evocar esse estado metal. Nesse sentido, a retradução apresenta certo distanciamento na recriação desse estado cognitivo que, de acordo com a análise empreendida, é evocado com mais proximidade pela tradução, particularmente no uso cumulativo da imperfectividade verbal.

No Quadro 2 apresentamos, resumidamente, um comparativo das escolhas lexicogramaticais discutidas anteriormente entre os três textos: 
Quadro 2: Resumo comparativo de escolhas tradutórias entre o original e as traduções

\begin{tabular}{|c|c|c|}
\hline Texto original (1985) & Traducão (1987) & Retradução (2006) \\
\hline \multicolumn{3}{|c|}{ Dêixis temporal } \\
\hline later & mais tarde & mais tarde \\
\hline then & depois & em seguida \\
\hline then & depois & depois \\
\hline \multicolumn{3}{|c|}{ Metáfora conceptual (símile) } \\
\hline like an afterimage & como uma pós-imagem & $\begin{array}{l}\text { como uma imagem } \\
\text { evocada }\end{array}$ \\
\hline \multicolumn{3}{|c|}{ Modalidade epistêmica } \\
\hline I thought I could smell & parecia-me poder sentir & imaginei que podia sentir \\
\hline I knew from pictures & $\begin{array}{l}\text { eu conhecia das } \\
\text { fotografias }\end{array}$ & $\begin{array}{l}\text { eu tinha visto em } \\
\text { fotografias }\end{array}$ \\
\hline $\begin{array}{l}\text { dances would have been } \\
\text { held there }\end{array}$ & na certa, ali havia bailes & $\begin{array}{l}\text { bailes teriam sido } \\
\text { realizados ali }\end{array}$ \\
\hline \multicolumn{3}{|c|}{ Objetos do mundo textual } \\
\hline $\begin{array}{c}\text { garlands made of tissue- } \\
\text { paper flowers }\end{array}$ & $\begin{array}{l}\text { grinaldas de flores de } \\
\text { papel crepom }\end{array}$ & $\begin{array}{l}\text { guirlandas feitas de flores } \\
\text { de papel de seda }\end{array}$ \\
\hline cardboard devils & diabos de papelão & máscaras de cartolina \\
\hline \multicolumn{3}{|c|}{ Processos } \\
\hline \multicolumn{3}{|c|}{ Mentais } \\
\hline thought & parecia & imaginei \\
\hline could smell & poder sentir & podia sentir \\
\hline$\emptyset$ & $\varnothing$ & evocada \\
\hline knew & conhecia & tinha visto \\
\hline$\varnothing$ & $\varnothing$ & assistindo \\
\hline$\emptyset$ & $\varnothing$ & ouvidos \\
\hline \multicolumn{3}{|c|}{ Comportamentais } \\
\hline slept & dormíamos & dormimos \\
\hline \multicolumn{3}{|c|}{ Existenciais } \\
\hline were gone & tivessem sumido & tivessem desaparecido \\
\hline \multicolumn{3}{|c|}{ Relacionais } \\
\hline had been & havia sido & havia sido \\
\hline was & era & era \\
\hline were & estavam & estavam \\
\hline shot through with & impregnado & mesclado \\
\hline lingered & pairava & $\varnothing$ \\
\hline$\varnothing$ & $\varnothing$ & coberta \\
\hline \multicolumn{3}{|c|}{ Materiais } \\
\hline painted & pintados & pintados \\
\hline were played & $\emptyset$ & eram disputados \\
\hline ran around & contornava & cercava \\
\hline$\varnothing$ & $\varnothing$ & vestidas \\
\hline$\varnothing$ & pintados & pintadas \\
\hline would have been held & havia (existencial) & teriam sido realizados \\
\hline made & $\emptyset$ & feitas \\
\hline$\varnothing$ & $\varnothing$ & seguindo-se \\
\hline powdering & salpicando & salpicando \\
\hline
\end{tabular}

Fonte: elaborado pelos autores. 


\section{Comentários Finais}

Com o intuito de contribuir para o desenvolvimento de estudos interlinguísticos sobre mundos textuais, este artigo se debruçou sobre a análise detalhada ${ }^{15}$ de representações mentais projetadas por elementos lexicogramaticais em um parágrafo do romance The Handmaid's Tale e de duas traduções brasileiras. Descrevemos como escolhas linguísticas atuaram na projeção de mundos textuais e na visualização de cenas descritas no excerto de abertura do romance. Evidenciamos o papel que a tradução pode exercer na projeção de mundos textuais, contribuindo para a projeção de modos diferentes de se conceptualizar o mundo referido pelo texto.

Uma das limitações da Teoria de Mundos Textuais é que, para ser aplicada a um texto em sua totalidade, é preciso que sejam textos mais curtos (cf. Gavins 2018), pela exigência de um nível fino de detalhamento, haja vista a diversidade e quantidade de categorias e perspectivas em análise. No caso de romances, a análise de todo o texto é impraticável; apenas excertos são geralmente considerados. Isso não significa que a teoria não possa ser aplicada em uma análise macrotextual. 0 detalhamento das análises dependerá dos objetivos do estudo. Desse modo, é uma teoria que favorece estudos contextualizados, que objetivam apreciar qualidades locais de textos, possibilitando a formulação de hipóteses a serem corroboradas em outros fragmentos textuais. Seus conceitos analíticos favorecem análises mais apuradas guiadas pelo texto e baseadas em princípios linguísticos, permitindo a comparação e discussão sistemática de representações mentais produzidas na leitura, favorecidas pelo uso da terminologia própria da teoria.

De modo geral, a Teoria de Mundos Textuais e a comparação interlinguística apresentam o potencial de revelar a multiplicidade de estratégias de construção conceptual discursiva. Muitas questões ainda permanecem em aberto, principalmente se considerarmos questões

\footnotetext{
${ }^{15}$ Dado o limite de espaço, fez-se necessário simplificar alguns aspectos analíticos.
} 
tradutórias, que incluem, por exemplo, mudanças em escolhas lexicogramaticais, que podem impactar o modo como o leitor constrói mentalmente o mundo referido pelo texto e o estado cognitivo evocado. Para ampliar o entendimento de como se dá a construção de mundos textuais em relações tradutórias, seus efeitos no mundo do discurso e vice-versa e como leitores respondem ao texto traduzido, mais estudos se fazem necessários.

\section{Referências bibliográficas}

Atwood, M. A história da aia. Rio de Janeiro: Marco Zero, 1987.

ATwood, M. O conto da aia. Rio de Janeiro: Rocco, 2006.

ATwood, M. The Handmaid's Tale. New York: Anchor Books, 1998 [1985].

BERMAN, A. La retraduction comme espace de la traduction. Palimpsests, n. 4, pp. 1-7, 1990.

BOASE-BEIER, J. Stylistic approaches to translation. London: Routledge, 2014.

CANNING, P. Text world theory and real world readers: from literature to life in a Belfast prison. Language and Literature, v. 26, n. 2, pp. 172-187, 2017.

CARNEIRO, R. Initial survey of English Canadian literature translated in Brazil: a historiographic perspective. In: Dêangeli, M. A.; Stupiello, E. N. A. (org.) Expressões e impressões da diferença (no prelo). 1. Ed. São José do Rio Preto: UNESP.

Carneiro, R. M. O.; Novodvorski, A. Entrevista com Felipe José Lindoso. Cadernos de Tradução, v. 40, n. 1, p. 308-322, 2020.

FAUCONNIER, G.; TURner, M. The way we think: conceptual blending and the mind's hidden complexities. New York: Basic Books, 2002.

Gavins, J. Text-worlds. In: Sotirova, V. (ed). The Bloomsbury companion to stylistics. London: Bloomsbury, 2018. pp. 444-457.

GaVINS, J. Text world theory: an introduction. Edinburgh: Edinburgh University Press, 2007.

Gavins, J; LAHEY, E. (ed). Discourse in the mind. London: Bloomsbury, 2016.

HALLIDAY, M. A. K.; MATTHIESSEN, C. M. I. M. Halliday's introduction to functional grammar. London: Routledge, 2014.

Jeffries, L.; MCINTYRE, D. Stylistics. Cambridge: Cambridge University Press.

Lakoff, G; Johnson, M. Metaphors we live by. Chicago: University of Chicago Press, 1980.

LANGACKER, R. W. Cognitive grammar: a basic introduction. Oxford: Oxford University Press, 2008. 
LeECH, G.; SHORT, M. Style in fiction: a linguistic introduction to English fictional prose. London: Pearson, 2007.

LUGEA, J. World building in Spanish and English spoken narratives. London: Bloomsbury, 2016.

NutTALL, L. Constructing a text world for The Handmaid's Tale. In: Harrison, C.; et al. Cognitive grammar in literature. Amsterdam: John Benjamins, 2014.

RYAN, M. L. Possible worlds, artificial intelligence and narrative theory. Bloomington: Indiana University Press, 1991.

RyAN, M. L. The text as world versus the text as game: possible worlds semantics and postmodern theory. Journal of Literary Semantics, v. 27, n. 3, pp. 137-163, 1998.

SEMINO, E. Language and world creation in poems and other texts. London: Routledge, 2014.

SEMINO, E.; CULPEPER, J. V. Cognitive stylistics: language and cognition in text analysis. Amsterdam: John Benjamins, 2002.

SIMPSON, P. Language, ideology and point of view. London: Routledge, 1993.

StockWELL, P. Cognitive poetics: an introduction. London: Routledge, 2002.

WERTH, P. 'World enough, and time' Deictic space and the interpretation of prose. In: Verdonk, P; Weber, J. J. (ed). Twentieth-century fiction: from text to context. London: Routledge, 2002. pp. 181-205.

WERTH, P. Text worlds: representing conceptual space in discourse. Harlow: Longman, 1999.

WHITELEY, S. Text world theory, real readers and emotional responses to The Remains of the Day. Language and Literature, v. 20, n. 1, pp. 23-42, 2011. 